Urban Policy and Research,

Vol. 24, No. 4, 433-453, December 2006

Routledge

Taylor \& Francis Crou

\title{
Investigating the Social Dimensions of Transport Disadvantage-I. Towards New Concepts and Methods ${ }^{1}$
}

JAGO DODSON, NICK BUCHANAN, BRENDAN GLEESON \& NEIL SIPE

Urban Research Program, Griffith University, Nathan Campus, Brisbane, Australia

(Received 7 September 2005; accepted 1 September 2006)

ABSTRACT This article is the first of two papers that engage critically and productively with the relationship between the socio-economic transformations of cities, the differentiation of vulnerable groups within urban space and the distribution of transport services. This article undertakes a comprehensive review of the major conceptual and methodological approaches by which scholars and policy researchers have sought to address the connection between social disadvantage and access to transport. The article critically assesses the relative merits of various spatial analytical methodologies in illuminating social-transport links. The study finds that there is a need for greater sophistication in the use of analytical methods in transport research as well as an imperative for greater sensitivity to social differentiation within urban areas and relative to infrastructure and services. The article concludes by developing a method for combining spatial social and transport service data that is then deployed in the empirical case study reported in the second paper.

KEY WORDS: Transport, social exclusion, urban planning, disadvantage, infrastructure

\section{Introduction}

Access to transport systems and the connection such systems provide to essential economic and social activities is a critical dimension of households' socio-economic wellbeing. However, in spite of ongoing social and economic changes in recent decades, scholars have been slow to draw the link between mobility, transport and social outcomes. This article is the first of two papers that undertake a comprehensive conceptual and methodological review of the ways scholars have contemplated the connection between transport disadvantage and social status. We show that transport and mobility are crucial components of social accessibility, and develop this argument in the second article via an empirical examination of the Gold Coast City. Our assessment demonstrates the critical importance of methodological capacities to illuminate the links between transport accessibility and social disadvantage. We suggest that while there are various

Correspondence Address: Jago Dodson, Urban Research Program, Griffith University, Nathan Campus, Brisbane, QLD, 4111, Australia. Email: j.dodson@griffith.edu.au

0811-1146 Print/1476-7244 Online/06/040433-21 (C) 2006 Editorial Board, Urban Policy and Research DOI: $10.1080 / 08111140601035317$ 
sophisticated existing transport assessment methods available to scholars, until recently there have been few such tools available that extend to enable the inclusion of social disadvantage as an additional dimension. We argue that this aspect of the transport and social methodologies remains immature and the coverage reporting of this area of research in the scholarly literature is underdeveloped. We argue that there remains much further work to be undertaken in this field. The article is timely given the rapid rate of development in the field and the lack of reports on Australian experiences.

Australian cities have been marked by three major socio-spatial shifts since the 1980s: the rise of the central city as a premium employment and housing location (O'Connor \& Healy, 2002), the growth of desirable fringe estates (Gwyther, 2002; Dodson \& Berry, 2003) and the decline of many of the older middle ring suburbs (Randolph, 2002). These urban structural changes, founded in structural political economic shifts (notably, economic globalisation), have both reflected and shaped new patterns of social disadvantage in the cities (Murphy \& Watson, 1994; Wulff \& Evans, 1999). However, the dynamic social structure of Australian cities contrasts with the slower evolution of their transport systems, which remain characterised by continuing, if contested, institutional and political support for automobiles as the dominant mode of urban travel (Newman \& Kenworthy, 1999; Mees, 2000). Many Australian metropolitan areas have developed in the absence of coherent and coordinated, infrastructure and transport planning. In Australia's large urban regions, including many of the subregions marked by new patterns of social disadvantage, public transportation remains underdeveloped (Mees, 2000). This inadequacy of transport infrastructure and services impedes access to employment and services, especially for vulnerable social groups.

There has been little scholarly analysis of how mobility and access patterns in Australian cities have been affected by the interplay of dynamic social structural change with the slow and imbalanced development of transport services. Overseas literature, especially British (Power, 2001), suggests that new patterns of urban social exclusion are intensified by, and indeed partially defined by, the inadequate supply of transport services and strengthening social demands manifested at the subregional level within cities. This 'mismatch' theme has been anticipated and to some extent was explored in earlier Australian urban literature (Morris, 1981). However, in recent years this has received little attention. Progressively development is witnessing the rise of new, if unexplored, patterns of urban mobility need, generated by the sorts of socio-spatial restructuring outlined above. Overall, the differential impacts of transport supply failures on various social groups are poorly understood. To address this gap in research-based knowledge of urban social mobility, we identify two pressing tasks for Australian scholars:

1. to identify how mobility status is best conceived in the wake of urban structural changes that have produced new patterns of social need and disadvantage, including the concept of 'social exclusion'; and

2. to consider how the variety of methods that have been used to measure social disadvantage and spatial immobility can best be combined and deployed to produce new understandings of transport status in Australia's contemporary cities.

These tasks constitute a major scholarly enterprise that can only be achieved through multiple investigations that trial and compare distinct methodological approaches in different cities, and through fulsome collegial discussion of their results. The modest aim 
of this two-part publication is to report on and further stimulate this important scholarly endeavour by presenting a review of concepts and methods relating to the study of transport and social status, by reporting the results of recent research in a major Australian city. This research was conducted as a pilot project, with outcomes of which we hope will initiate deeper scholarly engagement with the subject of transport disadvantage.

This article is the first of two papers that consider the links between social status and transport disadvantage. ${ }^{2}$ Together, the two papers will address and engage knowledge gaps relating to transport disadvantage in two ways. The first paper provides a review of approaches from different fields of discipline, with the emphasis on conceptual and methodological approaches to transport disadvantage, from an Australian perspective. We hope this article will contribute to greater scholarly and policy understanding while offering new approaches to the study of this critical feature of contemporary urbanisation. The subsequent second paper will apply these approaches to a case study area, and reports on findings arising from an empirical and methodological study of the Gold Coast City.

The current article reviews the literature to examine how researchers, scholars and policy makers have conceptualised the links between urban socio-economic processes, social status, transport needs and urban mobility. This review is framed within the broader context of ongoing socio-spatial restructuring of cities and the attempts by policy makers to manage and shape these impacts. The distributional impacts of these processes are also reviewed in terms of transport systems and the access they provide to employment and services. Having summarised this literature, the article then identifies methods of assessing transport disadvantage that could further improve knowledge of transport disadvantage.

\section{Urban Socio-spatial Change}

There is substantial literature concerning the patterns and dynamics of socio-economic disadvantage within cities. The processes of urban economic and social change that impact upon lower socio-economic status groups have been the focus of much research and analysis. Different disciplinary emphases have been apparent. For example, research into the phenomenon of spatial mismatch (Ihlanfeldt \& Sjoquist, 1998) developed from quantitative spatial analytical literature, while transport exclusion studies (Hine \& Mitchell, 2003) developed from social exclusion, not from spatial analysis. This section reviews the major urban socio-structural shifts in Australia and other Western nations to identify major patterns of change, the effects these changes have had on various social groups and the implications such transformations have in terms of access to employment and services.

\section{Urban Structural Change}

Since the late 1970s urban regions within Australia and other Western nations have experienced major transformations in their socio-spatial structures. Largely, these changes have been driven by economic changes associated with the most recent broad phase in the restructuring of global capitalist production, generally referred to as 'globalisation' (Fagan \& Webber, 1999). Within many Western cities, particularly those in which national welfare provision is weak, this restructuring process has resulted in greater spatial socioeconomic differentiation (Dodson \& Berry, 2003). 
The effects of ongoing globalisation have been particularly apparent in labour markets, both in Australia (Freestone \& Murphy, 1998; Brain, 1999; O'Connor \& Healy, 2002) and internationally (Sassen, 1988; Reich, 1991; Standing, 1999). For example, Sassen (1991) reported the spatial dimensions of this differentiation in global cities, with high-value informational 'producer services' employment concentrated in the 'global core' of cities, while production work was increasingly located in middle and fringe locations. Noting the implications of these restructuring processes in Melbourne, and their interaction with housing markets, O'Connor \& Healy (2002, p. 47) observed that:

In many respects, the core is job and skill rich, housing-expensive and an increasingly exclusive region. Indeed, a major contradiction within contemporary metropolitan Melbourne is the existence of an economically significant region that is becoming increasingly inaccessible as a place of residence.

It seems that location within the metropolitan urban structure has become a key determinant of households' and individuals' access to employment and other opportunities (Burke \& Hayward, 2000; Naess, 2005). Burke and Hayward (2000) revealed that limited housing affordability experienced by low-income households was excluding this group from inner areas, forcing them to less expensive outer urban locations. These changes have impacted disproportionately on disadvantaged groups of society.

\section{Social Exclusion in Divided Cities}

The differentiation of social status, and accordingly, opportunity across urban space has become a major feature of recent inquiry. Observation of the labour market and housing divisions that have opened up in Australia's major cities (Burke \& Hayward, 2000; O'Connor \& Healy, 2002; Dodson, 2004), reflect similar reports for other metropolitan areas (Freestone \& Murphy, 1998; Randolph, 2002). Such shifts have received much conceptual and empirical attention from urban researchers, and there has been a particular emphasis, informed by overseas reports, on the concept of the spatially 'divided city' (Fainstein et al., 1992; van Kempen \& Marcuse, 1997; O'Connor et al., 2001). Divided cities display high degrees of spatial differentiation between different socio-economic groups, and these distinctions can be observed in spatial housing and labour market patterns (Fainstein et al., 1992).

The related phenomenon of gentrification is one example of such processes re-shaping urban areas under the processes described above. Gentrification involving the movement of high-income and high labour market status populations to previously declining inner urban locations, results in housing market price shifts displacing the existing less advantaged residents (Smith, 1996). Such housing market shifts have been prominent features of urban socio-spatial change in recent decades (Logan, 1985; Zukin, 1988). This has been the case, particularly in many European and Australian cities, where the middle class has demonstrated a willingness to return to residing in the inner city. This shift has had important consequences for the distribution of access to important social resources, such as high-value employment (O'Connor \& Healy, 2002) as well as transport services (Morris et al., 2002).

The corollary of gentrifying groups' movement into the inner city has been the displacement of socio-economically weaker and disadvantaged inner city populations to 
outer urban locations (Freestone \& Murphy, 1998). As most of the outer suburbs of Australian cities were developed during the post-World War II shift to automobile-based urban planning, they have the most inadequate public transport services (Mees, 2000). Therefore, this socio-spatial restructuring of Australian outer urban areas has implications for transport provision, particularly in terms of social equity (Burnley et al., 1997).

The effects of divided cities from urban spatial and structural processes have been of substantial interest both internationally and nationally, with the least affluent end of the socio-economic spectrum receiving the majority of attention. Several authors have asserted that the forms of recent economic restructuring accompanying globalisation have produced new forms of spatially related economic and social disadvantage from those previously experienced in urban settings (Sassen, 1991; Smith, 1996; Madden, 2003). Such divisions have been described as social polarisation (Hamnett, 1994), social exclusion (Musterd \& Ostendorf, 1998), spatial segregation (Abramson et al., 1995; Andersen, 1998; Cheshire et al., 2000) and social marginalisation (Jamieson \& Jacobs, 1996; Wacquant, 1999).

As changing socio-economic urban spatial patterns became increasingly prominent during the 1990s, policy makers began to dedicate greater attention to the broader social, economic and policy consequences of these sharpened distinctions. In response to growing policy imperatives the phenomenon 'social exclusion' received much scholarly and policy attention, becoming an object of research. Social exclusion broadly captures the situation in which socio-economic circumstances prevent individuals or households, typically those at the lowest socio-economic level, and who are the most vulnerable to spatial restructuring processes, from accessing employment, adequate housing, and other social and community services (Peace, 2001). Characteristically, studies of social exclusion incorporate a strong spatial dimension. This can be seen in the segregation from those at the lower end of the wealth spectrum, from high quality housing markets, high-value labour markets and from good access to public services. For example, housing is most affordable in poorer, outer suburban areas of Melbourne (Wulff \& Reynolds, 2000), however, these less advantaged locations are not likely to be well served by public transport (Dodson, 2004).

\section{Exclusionary Urban Structure}

Changing urban structure has been implied in exclusionary processes, particularly in the USA. As suburban development has decentralised, often re-centring around freeway nodes, so too has employment (Garreau, 1991). The result of these patterns is that US inner city residents tend to face reduced access to high quality labour markets and more complex job search processes. Subsequently, inner city residents have longer commuting burdens than do residents of the middle and outer suburbs. Spatial structure therefore, is viewed by numerous scholars in the USA as implicated in the reproduction of social disadvantage for individuals and households located within inner city locations (Galster \& Killen, 1995). Such a phenomenon has been referred to as 'spatial mismatch' (after Kain, 1968) and has been the subject of much research in recent years (Holzer, 1991; Taylor \& Ong, 1995; Ihlanfeldt \& Sjoquist, 1998; Wachs \& Taylor, 1998; Sanchez, 1999; Brueckner \& Zenou, 2003). Studies of spatial mismatch are closely related to the methodologies they deploy. Consequently, the majority of research has been based around statistical models designed to identify specific variables influencing spatial employment access (Taylor \& Ong, 1995). 
The classic US case of an automobile-dependent city, resulting from a dispersed urban form and investment in freeways over public transport, also means that those individuals or groups who are unable to drive or afford automobiles are at a major mobility disadvantage in comparison to those able to drive or afford automobile ownership (Black, 1995). This mobility disadvantage in turn can impede with the employment opportunities of such groups, and can impinge upon government's social welfare objectives (Hughes, 1995). Thus, for example, if welfare recipients are forced by housing market processes (pricing and discrimination) to locate in disadvantaged inner city areas, they then potentially face fewer employment opportunities than comparable groups in the suburbs. In addition, if they are unable to afford car ownership, or if public transport is inadequate, then government objectives, such as encouraging higher employment rates among such households, are likely to be confounded by both the socio-spatial urban structure and the geographic and temporal provision of public transport services.

The relevance of the US spatial mismatch phenomena to Australia was recently tested in Melbourne. Dodson (2004) found that in contrast to typical US cities, the most socioeconomically disadvantaged areas in Melbourne were located in outer suburban locations, as opposed to the inner city. As outward suburban expansion has occurred, the number of available outer urban jobs also increased, gradually reducing spatial mismatch for disadvantaged outer suburban neighbourhoods. However, Dodson (2004) noted that the transport service quality and employment skill dynamics of this phenomenon remained unexplored. Transport may still play a role in impeding employment accessibility for residents of disadvantaged Australian outer suburban areas. This issue would be particularly exacerbated if residents of these areas do not possess the skills or qualifications to enable them to obtain employment in employment growth areas. As yet, there is not a sufficient body of Australian literature on this issue to make definitive conclusions about the extent or scale of spatial employment-housing mismatch. Nevertheless, there has been an awareness of the relationship between social disadvantage, location and transport, but this too remains underdeveloped. A particular problem seems to be that that transport has often been folded into general studies of broader disadvantage, rather than being a primary focus of study (Maher et al., 1992).

\section{Locational Disadvantage}

Limited attention was given to transport issues in relation to social disadvantage in Australia during the late 1980s. However, by the early 1990s, the concerns enunciated by academics and policy makers prompted a set of studies into the spatial problem of locational disadvantage in Australian cities. This research was also strongly informed by housing concerns. These studies occurred through the Federal Government's Social Justice Research Program into Locational Disadvantage — and generated a vigorous subsequent policy debate (Maher et al., 1992; Travers Morgan, 1992; Badcock, 1994; Beer, 1994; Maher, 1994).

The purpose of Maher et al.'s (1992) study was to investigate residential mobility, and to determine the extent to which socio-spatial processes operated to disadvantage some groups in terms of the attributes of the locations to which households were attracted or allocated. In their study, which formed the basis for much of the recent Australian discussion of locational disadvantage, Maher et al. (1992, p.15) offered the following conceptual description: 
Locational disadvantage is one element of a more general notion of social disadvantage. It results from an inability to access or to use effectively the whole range of facilities and resources which not only improve well-being but better position households to take advantage of resources available to improve their longer-term life chances.

Maher et al. (1992) argued that locationally disadvantaged areas are deficient in terms of the facilities and resources necessary to enable a 'satisfactory life', or, which require residents to undertake long journeys to access such resources. The transport network, and transport services are among the 'resources' available to households, and thus inadequate transport can be seen as a key element of locational disadvantage.

To operationalise the concept of locational disadvantage, Maher et al. using comparative longitudinal data from the 1981 and 1986 censuses, developed an index of local availability of services, and an index of accessibility to external services. The availability of transport services was only one component in this indexing process, which also included primary variables such as income and employment status. Maher et al. found three categories of locationally disadvantaged areas: inner city locations, older industrial suburbs and outer urban locations. The latter two categories matched those later identified by Baum et al.'s (1999) socio-spatial studies as 'vulnerable' to adverse socio-economic change, suggesting longitudinal durability of locational social disadvantage.

The Australian Government's National Housing Strategy (1992, p. 57) drew on the Maher et al. work arguing:

People without private transport, especially where public transport is not readily available are likely to be disadvantaged. In particular older people, young people and members of a car-owning household who cannot use the car, are more likely to have problems and/or longer travel times to services and jobs.

The locational disadvantage studies stimulated considerable debate as to whether a household's locational outcomes were the result of their residential choice within the structures of the housing market, relative to their means (Maher, 1994). One notable interlocutor questioned Maher's and others' interpretations of the data, suggesting that insufficiently detailed scaling of the analysis was masking forced residential moves by disadvantaged households to, for example, outer suburban areas with limited social and physical amenity (Badcock, 1994).

The emergence of concentrations of medium and high social status households on the urban fringe since the mid 1990s has complicated the understanding of locational disadvantage, given that these areas of new development are situated beyond the older higher disadvantage outer suburbs (Gwyther, 2002; Dodson \& Berry, 2003). As the work of Gleeson \& Randolph (2001), Gwyther (2002) and Dodson (2004) attests, the argument over the existence and causes of locational disadvantage in Australian cities remains under-researched. During the mid 1990s, due to the attention of the Federal Government there were few public transport improvements across outer suburbs of Australian cities. The issue has largely disappeared from the policy agenda and the Federal Government retains no current interest in urban public transport infrastructure, policy or finance. However, poor access to transport has been clearly linked to other forms and dimensions of disadvantage, both in Australia and in comparable jurisdictions overseas. 


\section{Transport and Disadvantage}

Historically, transport has been unevenly accounted for in discussions of urban social disadvantage in the UK, European and even Australasian context. This occurs particularly in relation to other dimensions of disadvantage such as housing quality, location and affordability, and labour market status. This omission is not the case in the USA, where research has typically focused more on the spatial structure than on the phenomenological dimensions of social exclusionary processes. Most notably in the UK, research on the specific transport dimensions of social disadvantage has developed from work relating to social exclusion.

Since the 1997 election of the UK Labour Government, the links between social exclusion and transport have received substantial scrutiny (Church et al., 2000; Power, 2001). The UK Government's White Paper on the Future of Transport (1998), clearly stated that transport was a key component of policies for boosting economic growth, employment and combating social exclusion. A subsequent study conducted by the UK Department for Transport, Local Government and the Regions (DTLR, 2000, p. 76) concluded that:

Households without a car, in a society in which household car ownership is the norm (peri-urban and rural areas), are 'socially excluded' within our definition of the term, since they cannot fully participate i.e. behave as the vast majority of society behaves.

The DTLR study recommended that local authorities undertake a comprehensive survey and planning process to ensure that the transport needs for socially excluded people were being either met or ameliorated. Specific recommendations were also made that addressed compounding issues of improving service coordination, fares and ticketing, and physical accessibility of public transport services.

This transport disadvantage research originated from social exclusion issues, and this basis is still represented in UK policy approaches dealing with transport disadvantage. The UK Social Exclusion Unit (2003) has responded to these social disadvantage and transport relationships by promoting the adoption of 'accessibility planning' among that country's local governments. Accessibility planning involves detailed assessment and planning at the local scale to improve residents' access to employment and services. This has been widely implemented in the UK and has been supported by central government guidance as to how local councils should undertake planning and assessment processes (Department for Transport, 2004), including assistance with software tools (Department for Transport, 2004). Lucas (2004) has noted that while planning policies may develop sophisticated methods and strategies for improving local accessibility, actual change 'on the ground' is

less assured. To date in Australia however, there has been little adoption of the 'social exclusion' discourse or substantive attention to accessibility issues in local government planning. The overall contribution of transport inequalities to broader processes of social disadvantage remains largely unconsidered by Australian policy makers.

\section{Distributional Impacts}

In Australia, distributional transport impacts have received some attention. Morris \& Wigan (1979) and Morris (1981) were among the earliest Australian authors to investigate 
social equity issues in transport research. Morris examined the extent to which Australia's urban public transport systems provided socially equitable levels of service to groups likely to suffer both social and mobility disadvantage due to inadequate transport provision. Groups considered at risk were those such as the needy, young people, disabled persons and the elderly. Morris (1981) mapped Melbourne's urban public transport system, demonstrating that public transport was unavailable or of poor quality in many areas of the city.

However, there has been no recent research in Australia investigating the links between household social status, urban location and access to employment or services, relative to the costs of transport. Although research in Melbourne by Morris et al. (2002) raised the importance of several of these links, the aforementioned constraints on travel were not fully addressed. This void in the literature is perplexing, both in light of the noted dispersed urban form of Australian cities, and the high levels of dependence on private motor vehicles for urban access and mobility (Newman \& Kenworthy, 1999; Mees, 2000). The case of New Zealand is however illustrative, where improvements to the vehicle emissions control regime were abandoned as a result of the impact increased vehicle costs would impose on low socio-economic groups (Denne et al., 2005).

One of the better recent examples of empirical research on the spatial dimensions of transport equity in Australia is Cheal's (2003) consideration of 'transit-rich' and 'transitpoor' areas of Melbourne. Cheal found that 83 per cent of Melbourne's population lived outside of transit-rich areas where transport services operated frequently, every day and offered multiple destination choices. Cheal's comparison of socio-economic characteristics found that households in transit-poor areas tended to be socio-economically worse off on average, when compared to those in transit-rich areas. Cheal (2003, p. 54) observed that:

Obviously, those living in transit poor Melbourne without cars are severely restricted in the times and destinations to which they can travel. This means that many people face a curtailment of their ability to participate in a range of activities that other people take for granted. Often they are reliant on the generosity of friends and family for simple and regular trips such as shopping. Where such generosity is not available they must either go without that trip or make the journey by taxi, both potentially costly options in their own ways.

The implication of Cheal's research is that those not residing inside transit-rich Melbourne are socio-economically worse off, compared to those who reside within this area. Implicitly, this suggests that transport contributes a significant component to the existing levels of social disadvantage. Given that housing is most affordable in the poorer, outer suburban areas of Melbourne (Wulff \& Reynolds, 2000; Dodson, 2004), these less advantaged locations are likely to be well outside transit-rich areas.

This issue of the inequitable distribution of public transport services, which can relieve the burden of automobile ownership on low-income households, is reflected in Battellino's (1997) study as reported by Mees (2002) of mode share in Sydney, and Morris et al.'s (2002) analysis of mode share and car ownership in Melbourne. Battellino (1997) found in Sydney that low-income outer urban areas had higher household vehicle ownership rates, and public transport carried a lower share of non-work trips, than wealthy areas. Mees (2002) explained this difference as being due to the lower quality public transport service 
available in outer Sydney. Poorer residents were effectively forced into higher rates of car ownership because of the uneven distribution of public transport investment across the metropolitan area. This raises similar social equity concerns and issues to those enunciated two decades previously by Morris (1981).

A similar phenomenon to that described for Sydney appears to be occurring in Melbourne. Morris et al. (2002) demonstrated that vehicle ownership is much higher in outer urban municipalities than in inner urban locations. This also appears to be the result of the inequitable distribution of public transport services across the metropolitan area. Drawing on Morris et al.'s findings, Dodson (2004) suggests that in Melbourne the mismatch between outer areas where housing is affordable and inner areas where public transport service is of good quality, compounds the exclusionary processes operating in the housing market. Similarly, as Mees (2002) notes, gentrification has exacerbated this inequity, as wealthier households displace poorer households from inner areas, thus also capturing a greater share of public transport subsidies. Black (1995) has also suggested that a similar process has been taking place in the USA.

Distributional impacts are not only spatially expressed. Several societal groups have been identified as more likely to experience transport disadvantage or transport-related social exclusion than others (Denmark, 1998; Wu \& Hine, 2003). Various authors have noted the effects of automobile-dominated transport policies on groups who are either unable to drive or who cannot afford automobile ownership (Bostock, 2001). Schaeffer \& Sclar (1975) detailed the various privations suffered by the poor, the elderly and the young in terms of their access to transportation. Black's (1995) work on public transport planning also noted 'special groups of users' or the 'transport-disadvantaged' including the poor, elderly, disabled people, the intellectually disabled and women. Hine \& Mitchell (2003) reported that in Scotland, women were more transport disadvantaged than men, rental households suffered greater disadvantage than owner-occupiers/purchasers, and that lower income groups in terms of their income paid more for their public transport, as well as having longer travel times to access the same services as higher income groups.

Debates over transport equity and gender issues have been cited regularly (Turner \& Niemeier, 1997). Dowling and Gollner (1997) argue that public transport systems inadequately meet women's mobility needs, due to poor service frequencies, insufficient operating hours and limited service integration. However, Mees (2002) argues conversely that promoting road-based transport policies in the name of gender equity will merely reproduce the kinds of car-oriented approaches that created an automobile-dependent urban transport system in which women are likely to suffer transport disadvantage.

Young people constitute a further group at risk of transport disadvantage. Brownlee \& McDonald (1992) suggest that transport disadvantage relating to the school journey, and to entertainment and leisure trips, is a significant problem for outer urban youth in Australia. This conclusion is supported by Winter's study which suggests that inadequate transport constrains the educational and social opportunities for this group. Ridgewell et al. (2005) demonstrated that children's school travel is highly constrained depending on where they live within the urban system. In recent years 'walking school buses' have emerged to address the lack of safe pedestrian routes between home and school. This response to the transport exclusion faced by young children attests to the extent to which the transport needs of this group are often not met (Mackett et al., 2003; Timperio et al., 2004).

Many groups are more likely to experience transport disadvantage or exclusion than others. The literature suggests that transport disadvantaged groups of the population 
potentially include:

- Low-income people

- Beneficiaries and/or unemployed

- Children and youth

- Women

- Elderly

- Disabled

- Outer urban dwellers

- Ethnic minorities.

Transportation planning has not always considered these disadvantaged groups of the population in the decision making process. In addition, these societal groups are often given little forethought when planning for motorways and other automobile-dominated infrastructure is undertaken (Fincher \& Jacobs, 1998). Individuals and/or households can potentially be in more than one of these groups at a time, with circumstances having the potential to compound accessibility to public transport. For example, an individual such as a low-income person may not have access to a car, as well as residing in an outer urban area predisposed to poorer public transport services (Naess, 2005).

Few, if any, scholars have investigated multiple factors relating to transport disadvantage. The second paper in this study of transport disadvantage will use the SEIFA Index of Disadvantage to identify areas of social disadvantage and to determine the accessibility of individuals and households in these areas to public transport. Derived from the Census, the SEIFA Index combines several different factors such as income, unemployment, skill level and other variables to reflect disadvantage in the form of a comparative index. This index incorporates many aspects of the transport disadvantaged groups identified in the present article.

Changing social, economic and environmental imperatives are shifting scholarly and policy attention towards ensuring urban transport systems provide for accessibility. This marks a shift away from earlier perceptions which actually limited mobility (Cervero, 1989; Newman \& Kenworthy, 1999). Previously, typical transport studies sought to ensure the mobility of urban populations, with a focus biased towards private vehicles as the primary mode of travel. Models of travel behaviour have been deployed to assess which activities stimulate travel and how the transport system provides for this mobility. By comparison, the alternative concept of accessibility denotes the ease and capacity of urban residents to access employment and services at the local and regional scale of analysis.

Accessibility focuses on the ease of achievement of the ends rather than the ease of achievement of the means of mobility. This entails a shift from a focus on traffic flows through road networks towards a focus on employment, goods and services and travel to these via multiple modes. This focus shift towards accessibility requires giving consideration to how urban systems are planned at the local and regional scale to ensure that households are not forced into long automobile trips by the spatial distribution of landuse activities or suffer long travel times due to inadequate public transport.

Transport planning has typically not investigated the social dimensions of travel and the differing levels of access for different social groups. There have, however, been some specific exceptions. Studies on physical mobility and disability have often included different social dimensions. Gleeson's (1999) study of disability, for example, engages directly with the constitutedness of mobility and disability. However, our concern in this 
study is not with the physical disablement constructed by the urban environment but with broader socio-economic relations, some of which may be physically expressed, that constitute the urban travel opportunities of various social groups.

The first half of this article reviewed how urban structural economic and social change in cities has impacted upon lower socio-economic status groups. This review found that Australia's cities have become divided as a result of these processes. Urban and transport processes have impacted disproportionately on particular and often vulnerable groups of society. Different approaches investigating social and transport disadvantage originated from different backgrounds. For example, social and transport exclusion research emerged from a policy background, while spatial mismatch research was more closely tied to mathematical models. Studies on locational disadvantage in the mid 1990s in Australia highlighted the need for more research to be undertaken at the household level. Therefore, the theme emerging from the literature relating to transport disadvantage is that certain methodologies, operating at different conceptual levels, have influenced research findings and have had a varying influence on policy directions in different Western countries.

\section{Methodological Approaches}

The review above has revealed various different approaches to understanding the processes of socio-spatial segregation and the related impacts on disadvantaged groups. It also established that the concerns of specific disciplines have strongly influenced the methodological approach used to investigate transport disadvantage and associated processes. For example, social exclusion research is closely tied to policy (especially in the UK), while spatial mismatch investigations are often dependent on qualitative spatial analytical methods (as often utilised in the USA). Since the results of many studies are closely tied to the methods used to obtain them, it is highly pertinent to review the major methodological approaches that have been used in transport and urban planning disciplines. Three major approaches are discussed; modelling, socio-spatial and qualitative analysis.

\section{Modelling}

Modelling has been a central technique in transport planning since the development in the 1950s and 1960s of computer technology capable of handling complex mathematical equations. Normally, it is deployed at an aggregate scale, opposed to a disaggregate level, depending on the nature of the data. Typically such analysis has been used to apply mathematical algorithms and formulae to estimate traffic patterns and the effects of future planning scenarios on urban transport outcomes. Gravity models, with four steps-trip generation, trip distribution, mode allocation, traffic assignment-and their derivatives often form the basis of these models (e.g. Wadell, 1997) and are often used to measure phenomena such as spatial mismatch (Cervero, 1989; Levinson, 1998). For many researchers and policy makers, for example, Black (1981), modelling eclipsed other, less technical, methodologies to become identical to transport planning. Transport models have been used to assess more general aspects of urban accessibility. For example, the study by Morris et al. (1979) incorporates a very basic model linking social disadvantage and transport accessibility.

Most urban transport modelling has been auto-dominated and focused on the needs and desires of auto-dependent transport users (Graham \& Marvin, 2001). Social disadvantage 
however has been rarely addressed via conventional transport modelling. There is much potential for the development of models that more closely address issues of transport disadvantage. However, there are few readily available models that can be used to assess the links between social status and transport disadvantage. Recent activity-based transport models offer some opportunities to illuminate accessibility patterns in urban areas (McNally, 2000; Wang \& Cheng, 2001).

Helling's (1998) study of intra-urban accessibility in Atlanta is a good example of this modelling approach. Helling used a gravity model based on road-based travel time and census data to measure accessibility to employment. This enabled Helling to demonstrate a reduction in accessibility, in terms of travel time between 1980 and 1990. Helling (1998) didn't attempt to consider social disadvantage however. Wang (2003) undertook a similar model-based investigation using Cleveland as a case study. Wang compared job proximity to job accessibility, where proximity was a simple distance measurement while accessibility took into account further factors such as modal access. Wang (2003) found that although low-income workers enjoyed relatively better job proximity, many had very poor job accessibility, due to their limited transport mobility resulting from low levels of motor vehicle ownership. Such a finding has implications for the current article given that labour market status is a component of the degree of transport disadvantage potentially experienced by an individual or household.

Currie's (2004) recent work on public transport gap analysis provides a fruitful advance in the use of transport models to assess social needs. Currie used a transport model that weighted origin zones by the social characteristics of the population. This enabled the calculation of 'need' per zone, relative to available public transport services. This model however undertook composite assessments of need and did not decompose need to different categories, such as age or unemployment.

Activity-based models of transport behaviour offer some potential to illuminate the relationship between social status and transport disadvantage. Activity-based transport models seek to determine travel demand at the individual or household level by modelling behaviour based on household characteristics and the attributes of the broader neighbourhood and metropolitan environment (Wang \& Cheng, 2001). These models offer potential for development into methods for analysing links between transport disadvantage and household travel status. However, such models also depend on detailed travel survey data that identifies sub-group characteristics. This data may not be available in sufficient sample sizes to give a comprehensive assessment of socio-spatial transport disadvantage experienced by sub-groups at a fine geographic scale, while other data-sets such as census or transport systems data is available at very detailed spatial scales. Further methodological development may in future assist to improve the analytical power of activity-based models for social transport assessment.

Despite recent evidence of some advances, such as those provided by Currie, the deployment of transport models to better account for social disadvantage across multiple social dimensions remains generally underdeveloped. Transport models have potential to improve the comprehension of social aspects of transport systems. There remains much work to be done in this area of investigation not only for the social assessment of transport networks, but also in interpreting this in social scientific fora. There is a further need for transport models to account for the qualitative differences in the levels and types of travel by various socially disadvantaged groups, such as to medical or rehabilitation services or other assistance agencies. Simultaneously this imperative must also be resolved at a 
sufficiently fine grained spatial scale to permit policy makers to effectively respond to social disadvantage through transport provision.

Socio-spatial Analysis

A second methodological approach to understanding urban accessibility and transport disadvantage that has been developed and expanded in recent years is the use of spatial analysis. The primary approach to socio-spatial analysis has been through the use of geographical information systems (GIS). While also at an aggregate level, socio-spatial analysis allows the combination of spatial information with other types of information to enable mapping of various characteristics of the transport system. The capacity of GIS can range from depicting basic information such as the spatial coverage of the public transport network to generating sophisticated multivariate analyses incorporating large numbers of complex calculations.

GIS differs from mathematical computer modelling in that it is less reliant on assumptions about the way urban systems work. Rather, it is reliant on the availability of empirical data-sets and the combination of these to generate spatial analyses and representations that were unfeasible without high-capacity computing technology. However, the empirical meanings that are derived from manipulations of social data remain open to criticism as being inadequately sensitive to the nuances of actual social behaviour. GIS is particularly useful for analyses of spatial disadvantage in relation to transport as it permits relatively easy calculation of spatial metrics. Thus, for example, the identification of locations where a given level of public transport service is unavailable becomes relatively easy with GIS once the necessary data is available.

Perhaps the most common use of GIS is in transport service coverage analysis, which identifies how many people have a given level of service based upon where they are located. Murray et al.'s (1998) discussion of public transport coverage in South East Queensland is an example of this kind of socio-spatial analysis. Murray et al. (1998) sought to assess the policy implications of access to public transportation in terms of proximity to public transport services among residents of the region. Access to public transport was termed 'suitable' based on residential proximity being within 400 metres. Using this threshold of suitability combined with statistical census residential location data, resulted in maps produced of areas within South East Queensland that had 'suitable' public transport.

Accessibility models based on GIS have emerged as planning tools in recent years although primarily in non-scholarly contexts (e.g. Pennycook et al., 2001). These efforts have increased in number since the UK Government requirement for local councils to prepare accessibility plans. Thus, for example, the ACCESSION software package has been promoted by the UK Department for Transport as a tool to assist with accessibility planning. This has led to the proliferation of 'Public Transport Accessibility Levels' (PTAL) methods to evaluate local scale accessibility, including for development assessment purposes. PTALs typically calculate travel times by walking and public transport as measures of accessibility. While PTALs are growing in use across the UK there has been little Australian adoption of such methods. Nor has there been much scholarly assessment or deployment of such methods.

Some scholarly reports are available however. Wu and Hine (2003) used a PTAL approach to measure transport accessibility in Belfast, Northern Ireland. This approach is a 
highly detailed measure of the spatial accessibility from any origin point to the public transport network. PTAL takes into account the walking access time from the origin (i.e. the residence) to public transport access points, the number of services available within the catchment and the level of service at the public transport access points (i.e. average waiting time) (Wu \& Hine, 2003). Wu and Hine used 400 metres as a measure of a maximum walking distance, and expanded their analysis to incorporate different periods of the day. However, they did not differentiate between the days of the week and the weekend. Nor did $\mathrm{Wu}$ and Hine seek to incorporate social data that could assist to illuminate how different vulnerable social groups are served by Belfast's public transport system. It is this linking of accessibility and social disadvantage analysis which is the focus of the present article. Ongoing research by Jones et al. (2005) demonstrates that much more work remains to be undertaken in this field, a task to which this article responds.

While socio-spatial analysis frequently incorporates GIS, to visualise, analyse and model geographical data, it is often done through quantitative methods. GIS studies typically do not describe the physical landscape of the urban environment. For example, in order to access public transport, there may not be adequate footpaths, creating a problem for mobility-limited people such as the disabled, the young, the elderly or those with children. There is also a social landscape that may discourage residents walking between their residence and the bus stop especially after daylight hours. These accessibility constraints are better understood through qualitative approaches.

\section{Qualitative Analysis}

A third major methodological stream in research into the links between social status, transport and accessibility is the use of qualitative methods. In this context qualitative methods are taken to include approaches which do not seek to quantify either the patterns of traveller behaviour or the characteristics of the transport system. Often data is collected using interviews or surveys which ask respondents about their travel behaviour or their experiences of travel and access to services.

A concise example of the use of qualitative methods in the investigation of the links between social status and transport disadvantage is the study undertaken by Hine \& Mitchell (2003). Hine and Mitchell used a combination of intensive survey and focus groups to assess the extent of transport need, and associated transport-related social exclusion in urban Scotland. This research involved a comparison between three different urban neighbourhoods: an inner suburb, a peripheral housing estate and a free-standing township. The researchers conducted household surveys for each locality, including gathering of basic demographic and household data, socio-economic information, and particulars on vehicle ownership and travel behaviour. Semi-structured interviews were also conducted with local authority planners and transport operators to develop understandings of transport and social exclusion from the policy and provider perspective. Although some of the information collected was quantified and presented in statistical form, much of the findings involved conveying non-quantified statements made by respondents, revealing the personal experiences of transport users. The Hine and Mitchell study also followed a geographically specific sampling method that illuminates general patterns at an aggregate scale but means the results are not necessarily generalisable across different localities even within the spatial categories (inner, peripheral, free-standing) that 
they assessed. This is one of the critical weaknesses with such qualitative methods-while one location may be poorly served, another adjacent may have good public transport services.

Hamilton \& Jenkins (2000) also used a qualitative approach to assess the adequacy of public transport services in meeting women's needs. Their qualitative methodology initially involved forming a theoretical and empirical understanding of women's travel needs. This understanding was then deployed to develop a 'checklist' against which agencies responsible for the provision of transport services (local authorities in the case of the UK) could assess the adequacy of those services. It is of some importance that Hamilton and Jenkins' approach differs notably from both conventional quantitative and qualitative approaches to understanding transport disadvantage which tend to focus on urban transport as a system, in which space, services and users interact with each other. Instead, the focus is on urban transport as an institution in which the service provider (such as a local authority) is assessed, based on its capacity, and consequently its success in providing an adequate level of service.

A further qualitative methodology that has been used to investigate transport disadvantage and exclusion is the 'community mapping' approach used by Johnson \& Herath (2004), based on similar approaches used elsewhere (Yearly et al., 2003). Johnson and Herath investigated the access to transport and services for residents of the socioeconomically disadvantaged area of Goodna in the outer western suburbs of Brisbane. Information gleaned from focus groups, community workshops and ongoing face-to-face discussions with residents identified the level of access residents perceived they had, relative to public transport, employment, and social and community services.

A particular benefit of this community mapping approach was that it enabled clear identification of local access barriers to transport and services faced by residents. Such barriers included the physical layout of the transport infrastructure in the study area, which in many instances impeded access rather than enhancing access. For example, the freeway running through the locality prevented access to the local rail station. Such local empirical factors could only be discovered via a local level qualitative investigation. Other methods, such as census data mapping or mathematical accessibility modelling would be unlikely to identify physical barriers that impede or impinge upon transport access at the community scale.

This methodological section of this article has described three main approaches used by different disciplines while investigating transport disadvantage and associated processes. Several drawbacks were presented in relation to modelling and transport processes, as modelling typically only incorporates aggregate scale processes and often favours road and automobile outcomes. It was noted that socio-spatial analysis, through the use of GIS, has the greatest current potential to illuminate problems of transport disadvantage, as, for example, spatial and temporal deficiencies of the public transport system can be easily quantified and depicted. GIS analysis also has the advantage of operating at multiple spatial scales, from the regional and metropolitan, down to the local. Depending on the availability of data, GIS can also incorporate different types of data, such as both physical and urban layout, temporal transit service availability and local social patterns. This mode of analysis forms the basis for the investigation undertaken in the second paper. Qualitative approaches also have the potential to be beneficial in the field of transport disadvantage, especially in regard to understanding how disadvantaged populations are affected. 


\section{Conclusion: New Methodological and Metropolitan Planning Ambitions}

Socio-spatial restructuring in Australian cities has been interwoven with the implementation of infrastructure policies that emphasise automobile use. These processes have left public transportation underdeveloped in Australia's largest metropolitan areas with the effect that many social groups are vulnerable to transport disadvantage. This issue has received increased attention from scholars in recent years, but it remains underexplored, particularly within the Australian context. In particular there is a critical lack of social scientific spatial research methodologies that can easily and comprehensively assess, depict and report transport disadvantage within Australian cities for the academic community and more broadly by policy makers. The project that this article contributes to seeks to advance social scientific inquiry into social and transport system relationships. This article has contributed to this task by reflecting critically on the capacities and potential for different avenues of methodological development.

This article has assessed the literature that examines the links between social status and transport disadvantage, and has identified some potential avenues for productive investigation. The review recognised the need to carefully comprehend the links between individual and household socio-economic status and how this affects their transport needs and opportunities within the broader context of urban socio-economic spatial and structural change. For reasons of data availability and methodological capacity this intersection of social concern and transport provision within the literature is relatively weak, especially within the Australian context. This weakness in turn limits the ability for academic research to inform policy making. While policy frameworks around 'accessibility planning' are being widely developed in the UK, we have not observed any substantial programmatic emergence of such a framework in the Australian context. The fostering of such a planning direction to more comprehensively link social assessment with transport analysis is clearly implied by the assessment and review undertaken in this article and the empirical analysis presented in the second paper.

Having examined the literature on transport disadvantage and social status, the article then tested various social scientific methodologies in terms of the conceptual and methodological capacities these offered in the links between socio-spatial and transport system patterns. The main methodological approaches of modelling and socio-spatial analysis were noted as being most appropriate to an aggregate level of analysis in which a high degree of abstraction was acceptable. Modelling, however, risks becoming excessively abstract to the point of not sufficiently reflecting empirical and particularly local conditions. By comparison, qualitative methods, while immensely useful in providing a richer experiential and local scale perspective on issues of transport disadvantage are often resource intensive and difficult to generalise beyond their local context to the scale of a metropolitan region. This article has sought to identify means of engaging with the problem of transport disadvantage analysis to identify methods that can in part overcome and mediate the problem of excessive abstraction or limited spatial scope, while incorporating empirical social and transport system data. Our review noted that the development of new research techniques to achieve the desired level of social and transport analysis is ongoing and that much work needs to be done. This article provides a timely review of the literature to date.

From the methodological approaches tested, it was identified that there were many benefits to using socio-spatial analysis in examining the spatial and temporal dimensions of 
transport disadvantage. In particular GIS methods continue to offer substantial scope for further methodological sophistication and refinement. This is particularly so as they are easily able to operate at the scale of an entire metropolitan area rather than either being restricted to local scales as is the case with qualitative methods, or being overly mathematically abstracted from the urban empirical context, which is the risk with modelbased approaches. GIS methods also offer the opportunity to combine multiple spatial datasets to assist analysis, such as socio-economic and transport system data, something that has not been substantially achieved with traffic models. For these reasons we consider that GIS methodological development is among the most fruitful avenues of inquiry for research that engages both the social and infrastructure/service dimensions of transport planning.

These findings inform the second paper which develops a GIS methodology to assess the extent of transport disadvantage in relation to socio-economic status, and deploys this methodology within the empirical context of Australia's Gold Coast City. Both papers demonstrate the need for greater scholarly and policy attention to issues of transport disadvantage. The development of new methodologies for comprehending and illuminating these pressing urban problems will help to address this imperative.

The second of these papers will appear in the March 2007 (Vol. 25, No. 1) issue of Urban Policy and Research.

\section{Notes}

1. This research was supported by the Gold Coast City Council and the Griffith University Industry Collaboration Incentive Scheme.

2. A complete description of this project can be found at the Urban Research Program's website: www.griffith. edu.au/centre/urp

\section{References}

Abramson, A. J., Tobin, M. S. \& Van Der Goot, M.R. (1995) The changing geography of metropolitan opportunity: the segregation of the poor in U.S. metropolitan areas, 1970 to 1990, Housing Policy Debate, 6(1), pp. 45-72.

Andersen, H. T. (1998) Social change and segregation in Copenhagen, GeoJournal, 46, pp. 7-16.

Badcock, B. (1994) Stressed-out' communities: 'out-of-sight, out-of-mind'?, Urban Policy and Research, 12(3), pp. $191-197$.

Battellino, H. (1997) Mode choice for non-work trips, 21st Australasian Transport Research Forum (University of South Australia: Adelaide).

Baum, S., Stimson, R., O'Connor, K., Mullins, D. \& Davies, R. (1999) Community Opportunity and Vunerability in Australia's Cities and Towns, (Melbourne: Australian Housing and Urban Research Institute).

Beer, A. (1994) Roasting an old chestnut: locational disadvantage, spatial inequality and government policy, Urban Policy and Research, 12(3), pp. 180-184.

Black, A. (1995) Urban Mass Transportation Planning (New York: McGraw-Hill).

Black, J. (1981) Urban Transport Planning (Baltimore and London: Johns Hopkins University Press).

Bostock, L. (2001) Pathways of Disadvantage? Walking as a mode of transport amoung low-income mothers, Health and Social Care in the Community, 9(1), pp. 11-18.

Brain, P. (1999) The Factors and Outcomes Driving Metropolitan Development over the Next Quarter Century (Melbourne: City of Melbourne and National Institute of Economic and Industry Research).

Brownlee, H. \& McDonald, P. (1992) A safe place for children: views from the outer suburbs, Family Matters, (December), 33, pp. 22-26.

Brueckner, J. \& Zenou, Y. (2003) Space and unemployment: the labor-market effects of spatial mismatch, Journal of Labor Economics, 21(1), pp. 242-266.

Burke, T. \& Hayward, D. (2000) Housing Past, Housing Futures: Melbourne Metropolitan Strategy Technical Report 4 (Melbourne: Department of Infrastructure). 
Burnley, I., Murphy, P. \& Jenner, A. (1997) Selecting suburbia: residential relocation to outer Sydney, Urban Studies, 34(7), pp. 1109-1127.

Cervero, R. (1989) Jobs-housing balancing and regional mobility, Journal of the American Planning Association, 55(2), pp. 136-151.

Cheal, C. (2003) Transit Rich or Transit Poor: Is Public Transport Policy in Melbourne Exacerbating Social Disadvantage? (Melbourne: Faculty of Architecture, Building and Planning, University of Melbourne).

Cheshire, P., Monastiriotis, V. \& Sheppard, S. (2000) Transforming Societal Inequality into Residential Segregation and Social Exclusion: The Role of Housing and Labour Markets (Liverpool: Neighbourhoods Colloquium, Economic and Social Research Council Cities Program).

Church, A., Frost, M. \& Sullivan, K. (2000) Transport and social exclusion in London, Transport Policy, 7 , pp. 195-205.

Currie, G. (2004) Gap analysis of public transport needs: measuring spatial distribution of public transport needs and identifying gaps in the quality of public transport provision, Transportation Research Record: Journal of the Transportation Research Board, 1895, pp. 137-146.

Denmark, D. (1998) The Outsiders: Planning and Transport Disadvantage, Journal of Planning Education and Research, 17(3), pp. 231-245.

Denne, T., Colegrave, F., Vuletich, S., Fisher, G. \& O’Brien, M. (2005) Vehicle Fleet Emission Screening Program: Social and Economic Impact Phase 1 (Auckland: COVEC Consultants and New Zealand Ministry of Transport).

Department for Transport (2004) Guidance on Accessibility Planning in Local Transport Plans (London: UK Government).

Department for Transport, Local Government and the Regions (2000) Social Exclusion and the Provision and Availability of Public Transport (London: DLTR).

Dodson, J. (2004) Is there a spatial mismatch between housing affordability and employment opportunity in Melbourne?. Conference on the State of Australian Cities, Urban Frontiers Program, University of Western Sydney, Parramatta.

Dodson, J. \& Berry, M. (2003) Community Regeneration in Melbourne's West? (Melbourne: Australian Housing and Urban Research Institute).

Dowling, R. \& Gollner, A. (1997) Understanding Women's Travel: From Transport Disadvantage to Mobility (Sydney: NRMA).

Fagan, R. H. \& Webber, M. (1999) Global Restructuring: The Australian Experience (South Melbourne: Oxford University Press)

Fainstein, S., Gordon, I. \& Harloe, M. (1992) Divided Cities: New York and London in the Contemporary World (Oxford and Cambridge, MA: Blackwell).

Fincher, R. \& Jacobs, J. (Eds) (1998) Cities of Difference (New York: Guilford Press).

Freestone, M. \& Murphy, P. (1998) Metropolitan restructuring and suburban employment centres: cross-cultural perspectives on the Australian experience, Journal of the American Planning Association, 64(3), pp. 286-298.

Galster, G. C. \& Killen, S. P. (1995) The geography of metropolitan opportunity: a reconnaissance and conceptual framework, Housing Policy Debate, 6(1), pp. 7-43.

Garreau, J. (1991) Edge Cities: Life on the New Frontier (New York: Doubleday).

Gleeson, B. (1999) Geographies of Disability (London: Routledge).

Gleeson, B. \& Randolph, B. (2001) Social Planning and Disadvantage in the Sydney Context (Sydney: Urban Frontiers Program, University of Western Sydney).

Graham, S. \& Marvin, S. (2001) Splintering Urbanism: Networked Infrastructures, Technological Mobilities and the Urban Condition (London and New York: Routledge).

Gwyther, G. (2002) Socio-spatial Differentiation and the Master Planned Community in a Global City Research Paper 8 (Sydney: Urban Frontiers Program, University of Western Sydney).

Hamilton, K. \& Jenkins, L. (2000) A gender audit for public transport: a new policy tool in the tackling of social exclusion, Urban Studies, 37(10), pp. 1793-1900.

Hamnett, C. (1994) Social polarisation in global cities: theory and evidence, Urban Studies, 31(3), pp. $401-406$.

Helling, A. (1998) Changing intrametropolitan accessibility in the US: evidence from Atlanta, Progress in Planning, 49, pp. 55-108.

Hine, J. \& Mitchell, F. (2003) Transport Disadvantage and Social Exclusion: Exclusionary Mechanisms in Transport in Urban Scotland (Aldershot: Ashgate).

Holzer, H. J. (1991) The spatial mismatch hypothesis: what has the evidence shown?, Urban Studies, 28(1), pp. $105-122$ 
Hughes, M. A. (1995) A mobility strategy for improving opportunity, Housing Policy Debate, 6(1), pp. 271-297.

Ihlanfeldt, K. R. \& Sjoquist, D. L. (1998) The spatial mismatch hypothesis: a review of recent studies and their implications for welfare reform, Housing Policy Debate, 9(4), pp. 849-892.

Jamieson, N. \& Jacobs, J. M. (1996) The making of marginalisation: highrise living and social polarisation, Restructuring Difference: Social Polarisation and the City Working Paper 6 (Melbourne: Australian Housing and Urban Research Institute).

Johnson, L. \& Herath, S. (2004) Big Roads, No Transport: A Report of the Goodna and Gailes Community Mapping for Transport Improvements Study, Research Monograph 5 (Brisbane: Urban Policy Program, Griffith University).

Jones, P., Wixey, S., Titheridge, H. \& Christodoulou, G. (2005) Developing Accessibility Planning Tools Working Paper 6 (London: Transport Studies Group, University of Westminster).

Kain, J. (1968) Housing Segregation, Negro Employment and Metropolitan Decentralizaiton, Quarterly Journal of Economics, 82(2), pp. 175-592.

Levinson, D. M. (1998) Accessibility and the journey to work, Journal of Transport Geography, 6(1), pp. 11-21.

Logan, W. S. (1985) The Gentrification of Inner Melbourne: A Political Geography of Inner City Housing (St Lucia: University of Queensland Press).

Lucas, K. (Ed.) (2004) Running on Empty: Transport, Social Exclusion and Environmental Justice (Bristol: Policy Press).

Mackett, R., Lucas, L., Paskins, J. \& Turbin, J. (2004) Cities for Children: the effects of car use on their lives, Walk21-V cities for People Conference, Copenhagen, Denmark, 9-11 June 2004.

Madden, J. F. (1996) Changes in the distribution of poverty in and across the US Metropolitan areas, 1979-1989, Urban Studies, 33(9), pp. 1581-1600.

Maher, C. (1994) Residential mobility, locational disadvantage and spatial inequality in Australian cities, Urban Policy and Research, 12(3), pp. 185-191.

Maher, C., Whitelaw, J., McAllister, A., Francis, R., Palmer, J., Chee, E. \& Taylor, P. (1992) Mobility and Locational Disadvantage within Australian Cities (Canberra: Department of Prime Minister and Cabinet Social Justice Research Program into Locational Disadvantage).

McNally (2000) The Activity Based Approach (Irvine, CA: Institute of Transportation Studies, University of Irvine).

Mees, P. (2000) A Very Public Solution: Transport in the Dispersed City (Melbourne: Melbourne University Press).

Mees, P. (2002) The road lobby goes post-modern: deconstructing the 'feminist car. Institute of Australian Geographers, Australian National University, Canberra, 12-16 July.

Morris, J. (1981) Urban public transport, in: P. Troy (Ed.) Equity in the City (Sydney: George Allen \& Unwin).

Morris, J. \& Wigan, M. R. (1979) Transport Planning: A Family Expenditure Perspective (Vermont South, Vic: Australian Road Research Board).

Morris, J., Dumble, P. L. \& Wigan, M. R. (1979) Accessibility indicators for transport planning, Transportation Research A, 13A, pp. 91-109.

Morris, J., Wang, F. \& Berry, M. (2002) Planning for public transport in the future: challenges of a changing metropolitan Melbourne, Australasian Transport Research Forum, Australian Bureau of Transport and Regional Economics. Canberra, 2-4 October.

Murphy, P. \& Watson, S. (1994) Social polarization and Australian cities, International Journal of Urban and Regional Research, 18(4), pp. 573-590.

Murray, A. T., Davis, R., Stimson, R. \& Ferreira, L. (1998) Public transportation access, Transportation Research D, 3(5), pp. 319-328.

Musterd, S. \& Ostendorf, W. (1998) Urban Segregation and the Welfare State: Inequality and Exclusion in Western Cities (London and New York: Routledge).

Naess, P. (2005) Residential location affects travel behaviour-but how and why? The case of Copenhagen metropolitan area, Progress in Planning, 63(1), pp. 167-257.

National Housing Strategy (1992) Housing Location and Access to Services: Issues Paper 5 (Canberra: Department of Health, Housing and Community Services).

Newman, P. \& Kenworthy, J. (1999) Sustainability and Cities: Overcoming Automobile Dependence (Washington: Island Press).

O'Connor, K. \& Healy, E. (2002) The Links Between Labour Markets and Housing Markets in Melbourne (Melbourne: Australian Housing and Urban Research Institute, Swinburne-Monash Research Centre).

O'Connor, K., Stimson, R. \& Daly, M. (2001) Australia's Changing Economic Geography: A Society Dividing (Melbourne: Oxford University Press). 
Peace, R. (2001) Social Exclusion: A concept in need of a definition?, Social Policy Journal of New Zealand, 16, pp, 17-36.

Pennycook, F., Barrington-Craggs, R., Smith, D. \& Bullock, S. (2001) Environmental Justice: Mapping transport and social exclusion in Bradford (London: Friends of the Earth).

Power, A. (2001) Social exclusion and urban sprawl: is the rescue of cities possible?, Regional Studies, 35(8), pp. $731-742$.

Randolph, B. (2002) Third city suburbs: options for housing policy in ageing middle ring suburbs, Australian Planner, 39, pp. 173-178.

Reich, R. (1991) The Work of Nations (New York: Alfred A. Knopff).

Ridgewell, C., Sipe, N. \& Buchanan, N. (2005) School Travel Modes in Brisbane Urban Research Program Research Paper 4 (Brisbane: Griffith University Urban Research Program).

Sanchez, T. W. (1999) The connection between public transit and employment: the cases of Portland and Atlanta, Journal of the American Planning Association, 65(3), pp. 284-295.

Sassen, S. (1988) The Mobility of Labor and Capital: A Study in International Investment and Labor Flow (Cambridge: Cambridge University Press).

Sassen, S. (1991) The Global City: New York, London, Tokyo (Princeton, NJ: Princeton University Press).

Schaeffer, K. H. \& Sclar, E. (1975) Access for All: Transportation and Urban Growth (Harmondsworth: Penguin).

Smith, N. (1996) The New Urban Frontier: Gentrification and the Revanchist City (London: Routledge).

Social Exclusion Unit (2003) Making the Connections: Final Report on Transport and Social Exclusion (London: UK: Government).

Standing, G. (1999) Global Labour Flexibility (Basingstoke: Macmillan).

Taylor, B. D. \& Ong, P. M. (1995) Spatial mismatch or automobile mismatch? An examination of race, residence and commuting in US metropolitan areas, Urban Studies, 32(9), pp. 1453-1473.

Timperio, A., Crawford, D., Telford, A. \& Salmon, J. (2004) Perceptions about the local neighbourhood and walking and cycling among children, Preventative Medicine, 38(1), pp. 39-47.

Travers, Morgan (1992) Strategies to Overcome Transport Disadvantage (Canberra: Department of the Prime Minister and Cabinet Social Justice Research Program into Locational Disadvantage).

Turner, T. \& Niemeier, D. (1997) Travel to work and household responsibility: new evidence, Transportation Research, 24, pp. 397-419.

UK Government (1998) New Deal for Transport: Better for Everyone; The Government's White Paper on the Future of Transport (London: UK: Government).

van Kempen, R \& Marcuse, P. (1997) A new spatial order in cities?, American Behavioural Scientist, 41(3), pp. 285-299.

Wachs, M. \& Taylor, B. D. (1998) Can transportation strategies help meet the welfare challenge?, Journal of the American Planning Association, 64(1), pp. 15-20.

Wacquant, L. (1999) Urban marginality in the coming millenium, Urban Studies, 36(10), pp. 1639-1647.

Waddell, P. (1997) Household Choice and Urban Structure: A Reassessment of the Behavioural Foundations of Urban Models of Housing Labor and Transportation Markets (Aldershot: Ashgate).

Wang, D. \& Cheng, T. (2001) A spatio-temporal data model for activity-based transport demand modelling, International Journal of Geographical Information Science, 15(6), pp. 561-585.

Wang, F. (2003) Job proximity and accessibility for workers of various wage groups, Urban Geography, 24(3), pp. $253-271$.

Wu, B. \& Hine, J. (2003) A PTAL approach to measuring changes in bus service accessibility, Transport Policy, 10 , pp. $301-320$.

Wulff, M \& Evans, S. (1999) The spatial impacts of commonwealth rent assistance on Australia's low-income households, in: M. Wulff \& J. Yates (Eds) Australia's Housing Choices (Queensland: University of Queensland Press and the Australian Housing and Urban Research Institute).

Wulff, M. \& Reynolds, M. (2000) Social polarisation and housing market change: a case study of Melbourne, 1986 to 1996, Australian Population Association 10th Biennial Conference: Population and Globalisation: Australia in the 21st Century. Australian Population Association, Melbourne, Australia, 28 November-1 December.

Yearly, S., Cinderby, S., Forrester, J., Bailey, P. \& Rosen, P. (2003) Participatory modelling and the local governance of the politics of UK air pollution: a three-city case study, Environmental Values, 12(2), pp. $247-263$.

Zukin, S. (1988) Loft Living (New York: Radius). 